\title{
Functional Grammar and Teaching of Reading-A Pedagogy Based on Graded Teaching of College English in China
}

\author{
Tuo $\mathrm{Xu}^{1} \&$ Beili Zhang ${ }^{2}$ \\ ${ }^{1}$ School of Foreign Studies, Nantong University, Nantong, China \\ ${ }^{2}$ Xinglin College, Nantong University, Nantong, China \\ Correspondence: Beili Zhang, Xinglin College, Nantong University, Nantong, 226007, China. Tel: \\ 86-158-5139-7299. E-mail: maximstime@gmail.com
}

Received: April 3, 2015 Accepted: May 18, 2015 Online Published: June 29, 2015

doi:10.5539/elt.v8n7p200 URL: http://dx.doi.org/10.5539/elt.v8n7p200

\begin{abstract}
This article discusses the importance of functional grammar and demonstrates its application to the teaching of reading among graded college students. Functional grammar holds that a discourse is composed of two levels: the interior level and the exterior level. Therefore, reading activities involve both linguistic elements and contexts. Implications of functional-grammatical view of reading are discussed, with techniques suggested for teaching of reading to English learners in the beginning and advanced proficiency levels.
\end{abstract}

Keywords: functional grammar, graded teaching in College English, teaching of reading, discourses, contexts

\section{Introduction}

Traditionally, teaching of reading in college English has been inclined to decompose discourses into units like glossary, phrases, sentence structures and grammar, demonstrate their usage and guide students to practice, which has detached the discourses from their context, whether it is context of situation or context of culture, and regarded reading activities as carriers of language input. This inclination, however, keeps in shadow the demonstrating functions of reading activities, and underestimates the meaning modes and contextual features of discourses. Researches of mother tongues have revealed that reading activities should not be confined to the explanation of linguistic features for literal meanings, whether they are vocabulary or grammar, but should involve cultural contexts and situational contexts and the shared background information of readers as well. By saying this, we mean that the comprehension of discourses should be an integrally coordinated process.

The purpose of this article is twofold. Our first goal is to give a brief overview of functional grammar as an integral model for reading activities and its being in compliance with the graded teaching of college English in China. Our second goal is to propose techniques of a functional-grammar-based pedagogy in reading classes among graded students learning English.

\section{Reading and Graded Teaching of English}

Gerot (2000) defines the nature of reading as "reading... (is) the task that takes as its input a body of text in a natural language and procedures as its output all understanding of that text." She also considers reading as the interaction between a reader and a text, holding that the reader is the language user and the text is an instance of language in use. Her view of reading is similar to that of Koda (2010), who holds that "reading comprehension is a meaning-construction process, involving integral interaction between text and reader". Readers construct the meaning of a text based on the linguistic elements, such as words, phrases, and sentences, and readers' language competence makes it possible for them to ascribe meaning or interpret meaning from a given discourse and to react to the socio-linguistic contexts reconstructed by the discourse. Therefore, as English teachers, we should endeavor to find a new teaching model in compliance with the nature of reading. We should take into consideration not only the accumulation of vocabulary, accuracy of spelling of words and pronunciation and the precise decomposition of grammatical structures, but the combination of writers' purposes and the contexts in which discourses were composed, so as to instruct language learners to grasp the meanings and functions of the discourses in a broad sense and help language learners improve their competence of outputs. Meanwhile, considering the levels and grades of language learners in colleges, we should apply different models to language learners of various linguistic proficiency, which is in accordance with the objectives of graded teaching of 
college English in China.

Here in this article, a new teaching model of reading will be constructed according to the guidebook issued by Ministry of Education of China in 2003, namely, College English Curriculum Requirements (For Trial Implementation). This guidebook requires that "the teaching of College English should follow the principle of providing different guidance for different groups of students and instructing them in accordance with their aptitude so as to meet the specific needs of individualized teaching." The strategy employed in this reform is to divide language learners into graded groups and teach them respectively. The prevalent model in most Chinese colleges is to grade students into A, B, C and D levels according to their scores in college entrance examination or diagnostic tests at the beginning of their college life, while students majoring in fine arts, PE and independent colleges will be graded respectively in the same way. Tarone and Yule (1999) argue that "A learner-focused teaching should meet the different demands of individuals to the largest extent". Therefore, we can arrive a safe conclusion that the practice of graded teaching of college English can meet the specific needs of individuals, arouse the enthusiasm of language learners at all grades, and inspire their potentials.

\section{Functional Grammar and Reading}

Functional grammar advocates to analyze discourses both at interior and exterior levels, which is of great significance and enlightenment to the teaching of reading. Interior analysis refers to the decomposition of linguistic devices employed by writers, and it involves the functions of basic linguistic units like clauses, theme-rheme structures, cohesive devices and coherence, and rhetoric devices and information structures, the objective of which is to cultivate language learners' capabilities of identifying and applying of grammatical units.

Exterior analysis involves the context or situation in which words are uttered and discourses are composed. Everything we say relates to a particular situation and words are not uttered independently of the context or situation. Therefore, in order to perceive a discourse thoroughly, we should analyze the field, tenor and mode of a particular discourse, all of which correspond to the metafunctions of all languages founded by Michael Halliday (1973), namely, ideational function, interpersonal function and textual function. From the perspective of functional grammar, discourse analysis should relate a given discourse to the systems of languages (Halliday, 2011). When it comes to the teaching of reading, we should consider a text as an integrity and probe into it from structural levels and its content, so as to facilitate language learners to grasp the main idea of the text efficiently and accurately.

Among above-stated two levels of discourses, the term of "theme-rheme structure" is much similar to the term of "subject-predicate" structure in traditional grammar, and thus possible confusion will be caused to language learners. However, the other terms and units of functional grammar are of many similarities to the grammatical categories and textual knowledge already perceived by college students. Therefore, it is practical and feasible to apply the two-leveled analyses in the teaching of reading, and hereinafter, based on the discourse theory in Functional Grammar, we will endeavor to design a much more desirable pedagogy for reading courses in graded teaching of college English.

\section{Implication for Teaching of Reading}

Theoretical framework of functional grammar suggests that the following procedure can be adopted when we analyze a particular discourse (Huang, 2001).

Context of Culture (Genre: Schematic structure and realizational pattern) - Context of Situation (Register: field, tenor and mode) - Discourse and semantics (Metafunctions: experiential function, logical function, interpersonal function, textual function (theme-rheme structure and information structure) and cohesive devices)-Use of language (Lexico-grammar and phonology or graphology).

Based on this framework and the objectives of graded teaching of college English, we can decompose the above framework reversely into two phrases, namely, use of language, discourses and semantics for language learners at the intermediate proficiency level, and context of situation and context of culture for language learners at the advanced proficiency level. This decomposition is actually intimately related to different levels of discourse comprehension as shown in Table 1, and hereinafter in sections 4.1 and 4.2, we will suggest patterns for language learners according to their proficiency levels respectively. 
Table 1. Language learners' phrases and levels of discourse comprehension

\begin{tabular}{lll}
\hline & Levels of Discourse Comprehension & Category \\
\hline \multirow{3}{*}{$\begin{array}{l}\text { Intermediate } \\
\text { Level }\end{array}$} & Meaning of phrases and clauses & Micro-level \\
\cline { 2 - 3 } & Discourse meaning & Macro-level \\
\cline { 2 - 3 } & $\begin{array}{l}\text { Indicating functions of key phrases to the } \\
\text { implication of discourses }\end{array}$ & Partial implications \\
\cline { 2 - 3 } & Implications of discourses & Integral implications \\
\hline $\begin{array}{l}\text { Advanced } \\
\text { Level }\end{array}$ & Context of Situation & Situation \\
\cline { 2 - 3 } & Context of Culture & Culture \\
\hline
\end{tabular}

Note: Table 1 has been adapted after the pattern suggested by Zhang Delu et al. (2005, p. 303).

\subsection{A Teaching Pattern for Language Learners at the Intermediate Proficiency Level}

Guidance for Academic Proficiency Test of Graded College English Teaching requires that students at the intermediate proficiency level should be able to read essays on general topics of intermediate difficulty, get an accurate comprehension of the main ideas, major facts and relevant details, and conduct analysis, inference and judgment on the content of the essays. In order to facilitate the practice in teaching, we can decompose the objectives of teaching into seven aspects as follows.

A: Identifying and understanding the main idea and important details

1) Understanding explicit concepts or details;

2) Understanding implicit concepts or details (e.g. conclusions, judgments and inferences);

3) Identifying the main idea of the passage (e.g. finding out the key phrases and clauses that can summarize the passage);

4) Understanding the points of view and attitudes of the author.

B: Understanding the passage with the help of relevant language skills

5) Inferring the meanings of phrases;

6) Understanding the elements of clauses, such as causes, results, purposes and comparisons;

7) Understanding the passage as a whole, such as lexical devices, and cohesive devices.

According to Adams (1990), accurate and fast identification of words is the most important predictor of reading capability, which is especially true for young readers. Therefore, teachers should lay emphasis on the analysis of language use in passages by making it more specific (namely, words, phrases and grammatical units) while probing into the semantic and cohesive devices as well, so as to help language learners perceive the functions of such devices for coherence of passages and get a panorama of the passages. Halliday (1994) holds that cohesion is realized by non-structural resources for the coherence of a given discourse and there are four ways by which cohesion is created, namely, reference, ellipsis, conjunction and lexical cohesion. These four ways contribute to the making of a coherent discourse through elements that are non-structurally related but semantically dependent. Therefore, language learners at the intermediate proficiency level should learn how to analyze these four ways of cohesion and perceive their functions for the integrity of passages.

In addition, the implied meanings in passages should be comprehended both at lexical level and discoursal level. To be exact, both the signifying functions of key words and the integrally implied meanings of passages should be approached to with the guidance of teachers.

\subsection{A Teaching Pattern for Language Learners at the Advanced Proficiency Level}

In Cultural Anthropology and Linguistics, H. Goodenough (1964) describes the relationship between language and culture as such: "the language of a society should be one aspect of the social culture, the relationship between language and culture is part and whole. As a specific aspect of culture, the unique point of language is that language is the main tool for human to learn culture. Human acquires the whole culture by studying and using language". A more recent definition between culture and language is made by Lubna Alsagoff (2010), who holds that "culture... can be identified based on race, religion, ritual practices... which is often associated with the use of the corresponding mother tongue of the ethnic groups". The relationship between language and culture is 
so close that language learners can not truly understand or use appropriately the foreign language without understanding the culture of the target language. Meanwhile, for advanced students, they are "already familiar with much of the language grammar... it is a case of re-presentation, rather than initial introduction of grammatical structure" (Johnson \& Morrow, 1982, p. 94). Therefore, teaching of reading to advanced learners should be beyond lexical and grammatical units, and should focus on the cultural background, social features, and the context of situation and context of culture represented by passages, with which advanced learners can understand and appreciate the passage as a whole.

Context of situation refers to the language environment in which the words, segments and sentences are formed, and contains three configurations mentioned in the beginning of this section, namely, field, tenor and mode. Field refers to the nature and topic between the interactants, tenor refers to the statuses and role relationships of the interactants, and mode refers to the media, rhetorical channels and linguistic styles involved in the interaction In an English class, for example, field in this case is concerned with English learning; tenor is the teacher and students, and the teacher's status is higher than those of students; mode is two-sided dialogue in teaching and practicing, whether it is spoken English or written English. Context of culture as a concept was first brought up by the famous anthropologist Bronislaw Malinowski, and it refers to the total way of life of a people, including the patterns of customs, traditions, social habits, values, beliefs and languages of a society. Compared with context of situation, context of culture is of much broader sense, much more abstract and much more difficult to comprehend, and can be said to be composed of context of situation and language. In sections 4.2.1 and 4.2.2, we will illustrate how to help advanced students at advanced proficiency level understand passages better by decomposing context of situation and piloting context of culture of passages.

\subsubsection{Decomposing Context of Situation}

When decomposing the context of situation of a particular passage, teachers should help students be acquainted with the field, tenor and mode of the passage in the following aspects:

Field: What is the main topic of the passage? What elements are the major verbs of sentences related to (that is, what are the major processes of the passage in terms of functional grammar)?

Tenor: Who are the interactants in the passage? What is the relationship between them? Is this relationship temporary or permanent?

Mode: Is the passage composed in spoken language or written language?

Based on the above decomposition, students will be able to appreciate the lexical choices and syntactical features of the passage, which will facilitate students to grasp the implied meanings of the passage. In this process, students should be guided to regard the passage as a whole and analyze the structure and content of the passage, so as to learn the major points of the passage and cultivate their communicative skills as well.

\subsubsection{Piloting Context of Culture}

Different from context of situation, context of culture cannot be measured and acquired by decomposition, and students can only by guided to comprehend the cultural background, history and customs of the community in the target language. It is generally believed that "background knowledge become an important variable when we notice, as many have, that students with a Western background of some kind learn English faster, on the average, than those without such a background" (Coady, 1979, p. 7). However, this process can never be said to be easy and be accomplished at one move, and it cannot be measures quantitatively or qualitatively. Therefore, teachers are suggested to arouse students' awareness of context of culture by following measures.

A) Guiding students to study the cultural background and social reality

Here we will take Studying Abroad (Unit 4, Section A in Book II compiled by Zheng Shu-tang et al., 2001) as an example. The author believes that it is no easy job to find a home-stay family in America, but Gloria managed to find two! When introducing her experience, Gloria says that "I even wrote about my four dogs and said I went to church every Sunday". Here, teachers are supposed to help students know the positive attitudes that Americans assume to pets, especially dogs. Meanwhile, about $82 \%$ of Americans believe in God, and religion prevails in every aspect of Americans' life from cradles, growing-up, marriages to graves. Therefore, Gloria's knowledge of Americans' affection to dogs and religion helps her to impress Americans deeply and positively. If students have no idea with Americans' affections towards dogs and religion, they will be unable to know the roles dogs and churches play in Gloria's success in finding two home-stay families.

"Comprehension is an interactive process between the reader's background knowledge and the text" (Carrel \& Eisterhold, 1983, p. 556). Readers have a strong tendency to relate new information to their prior experience or 
what they have already known about a given topic. By bridging the gaps between their culture and the culture of a given target language, unfamiliarity is decreased, interest is aroused, and accurate prediction in reading is possible.

\section{B) Comparing Western Culture with Chinese Culture}

There are considerable differences between western culture and Chinese culture in which Chinese students have been fostered, and such differences represent themselves in forms of diverse patterns, grammatical systems and pragmatic principles between English and Chinese. Therefore, as teachers, we should instruct students to be acquainted with the differences between western and Chinese cultures, so as to eliminate the cultural barriers in their readings. Otherwise, students will focus on surface structures of the English language while ignoring the cultural factors behind them, which will cause misunderstandings and incompetence of acquiring the concrete situations of language application.

Here we will take words of colors for example. When dealing with such words, teachers can compare and contrast red, black and white with their equivalents in Chinese by identifying their natural similarities in reference to colors and their cultural disparities in their respective cultures. As to idioms like as strong as a horse, teachers should elaborate them together with explanations of the development of western productivity, so as to help students learn English under its cultural background and grasp the profound implications in its culture.

C) Cultivating Cross-cultural Awareness by Constructing Communicative and Interactive Language Lessons

Cultural awareness in language teaching is the ability to be aware of cultural relativity following reading, writing, listening and speaking. As Claire Kramsch points out:

If... language is seen as social practice, culture becomes the very core of language teaching, cultural awareness must then be viewed as enabling language proficiency... (Claire Kramsch, 1993, p. 23).

Therefore, there is a good reason to say that language itself has been defined by culture and language competence cannot be achieved without excellent knowledge of the culture that shapes it. The goals of foreign language education at college level are redefined by the AdHoc Committee on Foreign Languages of the American Modern Language Association in accordance with the increasingly interconnected world which we are preparing our students to operate in.

The goal ... would not be simply to produce graduates better prepared to meet a range of identified national or societal needs, although this alone would be of significant value. Our goal is a higher education system that embraces the distinctive educational benefits of studying foreign languages and cultures in developing the powers of the intellect and the imagination, the ability to reflect on one's place in the world with depth and complexity, and understanding of the degree to which culture and society are created in language (MLA, 2008, p. 288).

However, the orientation of demonstrating the culture of the target language doesn't necessarily mean requiring language learners to identify such culture, but to help them acquire cross-cultural awareness as well as the initiatives to communicate. Therefore, teachers are not supposed to cram cultural knowledge into students. Instead, they should instruct students to accumulate such knowledge independently.

In English reading classes, teachers can guide students to surf the Internet for topics related to the title and topic sentences of a particular text, which will help students know more about the culture of English-speaking countries and cultivate their capabilities of evaluating, judging and perceiving the English language. Meanwhile, teachers are supposed to encourage students to recommend their favorite English books or articles to classmates and define their reasons. In this way, students can enhance their interests in reading, their horizons can be broadened due to their different preferences of reading subjects, and their access to the culture of the target language can be optimized.

\section{Conclusion}

An excellent reading capability is one of the basic objectives of college English teaching, and reading has always been a significant input in college English teaching. Meanwhile, reading comprehension in English tests such as CET-4 and CET-6 accounts for much larger percentage than other sections, and has been an emphasis as well as difficulty in English learning. Considering the characteristics of graded college English teaching, the teaching of reading within the framework of functional grammar can not only enhance students' competence in tests, but improve their capabilities of application and communication. Meanwhile, such enhancement and improvement can help build students' perception of English and mastery of the details and the overall layout of a particular discourse. 
Of course, the long-range goal of teaching of reading is not confined to classrooms, but should be extended to develop independent readers outside the classrooms and help students read in English to learn from what they read. Possibly more importantly, the pedagogy we have described in this article can prepare students to identify and deal with context of situation and context of culture, make them more sensitive to such elements when they read on their own, and ultimately, read between lines.

\section{References}

Adams, M. J. (1990). Beginning to Read: Thinking and Learning about Print. Cambridge, MA: MIT Press.

Carrell, P. L., \& Eisterhold, J. C. (1983). Schema Theory and ESL Reading Pedagogy. TESOL Quarterly, 17(4), 553-573. http://dx.doi.org/10.2307/3586613

Coady, J. (1979). A Psycholinguistic Model of the ESL Reader. In R. Mackay, B. Barkman, \& R. R. Jordan (Eds.), Reading in a Second Language (pp. 5-12). Rowley. Massachusetts: Newbury House Publishers.

Gerot, L. (2000). Exploring Reading Processes. In L. Unsworth (Ed.), Researching Language in Schools and Communities: Functional Linguistic Perspectives. London: Cassell.

Goodenough, W. H. (1964). Cultural Anthropology and Linguistics. In D. Hymes (Ed.), Language in Culture and Society: A Reader in Linguistics and Anthropology. New York: Harper and Row.

Halliday, M. A. K. (1994). An Introduction to Functional Grammar. London: Edward Arnold.

Halliday, M. A. K. (2011). Text, Discourse, and Information: A Systemic-functional Overview. Journal of Peking University, 48(1), 137-146.

Halliday, M. A. K. (1973). Explorations in the Functions of Language. London: Edward Arnold.

Huo, G. (2001). Discourse Analysis in Functional Grammar. Foreign Languages and Their Teaching, 12, 1-19.

Johnson, K., \& Morrow. (1982). Communicative syllabus design and methodology. Oxford: Pergamon.

Johnson, K. (1982). Communicative Syllabus Design and Methodology. Oxford: Pergamon.

Koda, K. (2010). The Role of Reading in Fostering Transcultural Competence. Reading in a Foreign Language, 22(1), 5-10.

Kramsch, C. (1993). Context and Culture in Language Teaching. Oxford: Oxford University Press.

Lubna, A. (2010). English in Singapore: Culture, capital and identity in linguistic variation. World Englishes, 29(3), 336-348. http://dx.doi.org/10.1111/j.1467-971X.2010.01658.x

MLA AdHoc Committee on Foreign Languages. (2008). Transforming college and university foreign language departments. The Modern Language Journal, 92(2), 287-312.

Tarone, E., \& Yule, G. (1999). Focus on the language learner. Oxford: Oxford University Press.

Zhang, D. et al. (2005). Functional Linguistics and Foreign Language Teaching. Beijing: Foreign Language Teaching and Research Press.

Zheng, S. (2001). New Horizon College English (Reading and Writing: Book II). Beijing: Foreign Language Teaching and Research Press.

\section{Copyrights}

Copyright for this article is retained by the author(s), with first publication rights granted to the journal.

This is an open-access article distributed under the terms and conditions of the Creative Commons Attribution license (http://creativecommons.org/licenses/by/3.0/). 